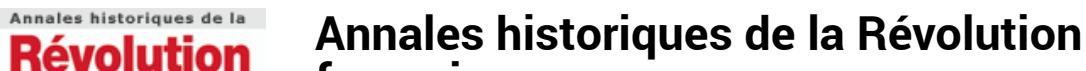

française française

370 | octobre-décembre 2012

Varia

\section{Michel BIARD (Ed.), Procès-verbaux de la Société}

populaire de Honfleur (Calvados) (janvier 1791février 1795)

\section{Côme Simien}

\section{(2) OpenEdition}

\section{Journals}

Édition électronique

URL : https://journals.openedition.org/ahrf/12540

DOI : $10.4000 /$ ahrf. 12540

ISSN : 1952-403X

Éditeur :

Armand Colin, Société des études robespierristes

\section{Édition imprimée}

Date de publication : 1 décembre 2012

Pagination : 238-240

ISBN : 978-2-200-92762-2

ISSN : 0003-4436

\section{Référence électronique}

Côme Simien, « Michel bIARD (Ed.), Procès-verbaux de la Société populaire de Honfleur (Calvados) (janvier 1797-février 1795) », Annales historiques de la Révolution française [En ligne], 370 | octobredécembre 2012, mis en ligne le 28 janvier 2013, consulté le 22 avril 2022. URL : http:// journals.openedition.org/ahrf/12540; DOI : https://doi.org/10.4000/ahrf.12540

\section{Ce document a été généré automatiquement le 22 avril 2022}

Tous droits réservés 


\title{
Michel BIARD (Ed.), Procès-verbaux de la Société populaire de Honfleur (Calvados) (janvier 1791-février 1795)
}

\author{
Côme Simien
}

\section{RÉFÉRENCE}

Michel BIARD (Ed.), Procès-verbaux de la Société populaire de Honfleur (Calvados) (janvier 1791février 1795), Paris, Éditions du CTHS, 2011, 820 p., ISBN : 978-2-735-50757-3, $60 €$.

1 Le présent volume poursuit, quatre ans après l'édition des procès-verbaux de la Société populaire de Crépy-en-Valois, une collection entièrement consacrée à la publication de ce type de sources. En s'appuyant sur une très riche documentation, pour l'essentiel conservée aux archives municipales de Honfleur, Michel Biard nous offre ici la lecture de quatre années ininterrompues d'activités d'un club jacobin normand, installé le 30 janvier 1791 par dix-huit pères fondateurs. La société des Amis de la Constitution de Honfleur appartient donc à la première génération de sociétés populaires du Calvados, qui n'en a vu naître que six en 1790 puis six autres en 1791, dans les chefs-lieux de districts et de cantons les plus importants (à l'image de Honfleur et de ses 8000 à 9000 habitants). Ce type de sociabilité politique restera par la suite peu fréquent dans un département où seules 50 communes sur 903 en compteront une au plus fort de la Révolution.

2 Formé d'abord dans le but de «se procurer avec plus de facilité la connaissance des affaires publiques de la France» par l'intermédiaire de journaux variés auxquels la société ne cessera plus de s'abonner ou de se désabonner au gré des fortunes diverses connues par ces titres, le club honfleurais nous donnerait presque à voir une société populaire "normale", tant son désir de se conformer aux modèles voisins, locaux et nationaux, est omniprésent. Évoquant en janvier 1791 le cas des villes qui ont imité «l'exemple de la capitale », les patriotes honfleurais estiment devoir « rivaliser » avec 
ces localités déjà dotées de clubs. Lorsqu'en février l'on décide d'établir une carte de membre, c'est que " toutes les sociétés voisines et étrangères étaient munies » d'un tel document. Ce conformisme, dont la prudence se laisse discerner par les adresses transmises à la Convention nationale pour la féliciter d'avoir su déjouer les complots des Exagérés, des Indulgents puis des Robespierristes au cours du printemps et de l'été 1794, ne doit cependant pas, pour Michel Biard, être confondu avec une quelconque forme d'opportunisme ou, pis encore, de couardise. À Honfleur comme dans d'autres sociétés populaires, l'adaptation aux retournements de la conjoncture traduit surtout un souci de la légalité et le souhait de faire passer la "volonté générale » avant les positions partisanes au nom de l'intérêt supérieur de la République. Cela ne veut donc pas dire que le club s'est contenté de subir le mouvement révolutionnaire. L'activité est intense. Si elle est souvent consacrée à des questions d'organisation interne, cette préoccupation même témoigne du désir de structurer le microcosme patriote en un corps social régénéré (en avril 1791 on parle d'ailleurs de "règlement social d'organisation »). Médiatrice et pédagogue des idées nouvelles, la société contribue à diffuser dans la ville et ses environs, par des affiches ou par l'envoi répété de commissaires (leviers privilégiés de son action), les principes révolutionnaires et les pratiques démocratiques naissantes. Tel est aussi le cas lorsqu'en juin 1791 le président de la société propose d'accueillir en son sein aussi bien les citoyens actifs que passifs, ouvrant un premier espace de délibérations politiques à ces derniers. Par ailleurs, la société est un véritable acteur local de la chose publique, en faisant tomber dans son champ d'intervention des questions de plus en plus nombreuses (effort de guerre, marine, secours aux indigents, éducation, certificats de civisme...). Relais des décisions des autorités locales lorsqu'elles lui semblent satisfaisantes, elle cherche aussi à influer sur la municipalité (problème récurrent des prêtres réfractaires en particulier) et n'hésite pas à exprimer sa désapprobation lorsque les décisions publiques lui semblent trop timorées (émigrés, septembre 1792). Á partir de pluviôse an II, la société devient même le « centre d'impulsion révolutionnaire majeur dans la ville et dans le canton ". Cela ne devait pourtant pas durer. Comme dans de nombreuses autres sociétés, la question de l'absentéisme et les moyens à mettre en œuvre pour le juguler reviennent maintes fois la hanter, surtout passé le 9 thermidor. Á compter de brumaire an III, certaines séances sont annulées faute de participants. L'énergie était brisée. Le 19 pluviôse an III, avant même que la Convention nationale n'ait décrété la fermeture des clubs, la société populaire de Honfleur clôture au son des "acclamations ordinaires » son ultime séance.

On regrettera bien sûr le silence des procès-verbaux à l'occasion de certains moments clés de la Révolution. La société ne se réunit plus, ou du moins ne couche plus sur le papier le fil de ses séances, entre le 23 juin et le 24 août 1793 alors que la révolte fédéraliste bat son plein en Normandie. On regrettera d'autant plus cette interruption que Honfleur est l'une des rares municipalités normandes à prendre le parti de la Convention montagnarde. On sait toutefois qu'à la fin juin, le président de la société, sans doute en raison de son soutien au mouvement fédéraliste, démissionne de son poste. De plus, dès ses premiers mois d'existence, les officiers municipaux successifs sont presque tous membres du club. En tout état de cause, sa position ne devait donc pas être trop différente de celle de la municipalité, rapidement hostile au soulèvement. La société a donc pu jouer un rôle dans la prise de position jacobine de Honfleur. Cependant, aussitôt les événements terminés, alors que plusieurs membres de la municipalité ont été destitués par les représentants du peuple en mission en raison de 
leur manque d'« énergie » lors des troubles, la société plaide en leur faveur, arguant d'un simple égarement momentané, ce qui permet à ces anciens détenus de réintégrer la société où continuent de siéger leurs accusateurs du comité de surveillance. On touche ainsi à l'une des autres préoccupations constantes de la société : assurer l'unité de la famille patriote, vœu déjà bien exprimé lors de la scission, à Paris, à l'été 1791, des jacobins et des feuillants, qui avaient vu la société honfleuraise appeler à leur réunification.

D'utilisation aisée grâce à des chapeaux introductifs résumant le contenu de chaque séance, l'ouvrage est encore parfaitement servi par une introduction qui restitue les contextes locaux, régionaux et nationaux indispensables à la mise en perspective du travail de la société. Ces prolégomènes d'une cinquantaine de pages offrent, de plus, un aperçu complet de l'activité, des débats ou de l'organisation de cet espace de sociabilité qui contribua localement à l'expérimentation des formes de l'innovation politique. Au fil des pages, un appareil critique important fournit toutes les informations nécessaires pour éclaircir les sous-entendus, les noms de personne, les titres de journaux, les dates et le contenu de décrets, en recourant à l'occasion à des documents d'archives complémentaires, tandis que des renvois nouent avec profit les liens de certaines prises de décisions au long cours. 89 pages d'annexes clôturent le volume par une abondante correspondance et le tableau des membres de la société (320 au total). Ce dernier, comprenant date d'admission, responsabilités et professions de quelques 204 citoyens, rend possible une analyse de la composition socio-professionnelle du club, qui témoigne de la surreprésentation du milieu des capitaines et des officiers de marine ainsi que de celui des marchands et des négociants, au détriment du monde du petit commerce, du petit artisanat et des marins. Enfin, les cartes et graphiques proposés permettront d'apprécier les questions de la périodicité des réunions de la société (plus nombreuses en juin 1791 et à l'automne 1792, plutôt moins fréquentes en l'an II) ou de la morphologie de ses réseaux, naturellement denses en Normandie (vingt-six clubs correspondants), néanmoins tissés à l'échelle nationale (quarante-trois autres localités recensées).

Michel Biard nous permet ainsi, page après page, d'évoluer au plus près des citoyens de la première moitié de la décennie 1790 et de leurs expérimentations démocratiques. De la fenêtre honfleuraise, c'est l'histoire du temps tel qu'il pouvait être vu et vécu par des révolutionnaires provinciaux qui nous est révélée et expliquée. Ce n'est bien sûr pas la moindre des qualités de ce volume qui, nous l'espérons, en appellera d'autres dans cette collection. 